\title{
Neuroligins Nlg2 and Nlg4 Affect Social Behavior in Drosophila melanogaster
}

\author{
Kristina Corthals ${ }^{\dagger}$, Alina Sophia Heukamp ${ }^{\dagger}$, Robert Kossen, Isabel Großhennig, Nina Hahn, \\ Heribert Gras, Martin C. Göpfert, Ralf Heinrich and Bart R. H. Geurten*
}

Department of Cellular Neurobiology, Institute for Zoology and Anthropology, University of Göttingen, Göttingen, Germany

\section{OPEN ACCESS}

Edited by:

Patrick Callaerts,

Flanders Institute for

Biotechnology, Belgium

Reviewed by:

Bruno Van Swinderen,

The University of Queensland,

Australia

Brigitte Dauwalder,

University of Houston,

United States

Jean-Christophe Billeter,

University of Groningen,

Netherlands

*Correspondence:

Bart R. H. Geurten

bgeurte@gwdg.de

tThese authors have contributed equally to this work.

Specialty section:

This article was submitted to Molecular Psychiatry, a section of the journal Frontiers in Psychiatry

Received: 17 February 2017 Accepted: 12 June 2017

Published: 10 July 2017

Citation:

Corthals K, Heukamp AS, Kossen R, Großhennig I, Hahn N, Gras H, Göpfert MC, Heinrich $R$ and Geurten BRH (2017) Neuroligins NIg2 and NIg4 Affect Social Behavior in

Drosophila melanogaster.

Front. Psychiatry 8:113.

doi: 10.3389/fpsyt.2017.00113
The genome of Drosophila melanogaster includes homologs to approximately one-third of the currently known human disease genes. Flies and humans share many biological processes, including the principles of information processing by excitable neurons, synaptic transmission, and the chemical signals involved in intercellular communication. Studies on the molecular and behavioral impact of genetic risk factors of human neuro-developmental disorders [autism spectrum disorders (ASDs), schizophrenia, attention deficit hyperactivity disorders, and Tourette syndrome] increasingly use the well-studied social behavior of $D$. melanogaster, an organism that is amenable to a large variety of genetic manipulations. Neuroligins (Nlgs) are a family of phylogenetically conserved postsynaptic adhesion molecules present (among others) in nematodes, insects, and mammals. Impaired function of Nlgs (particularly of $\mathrm{Nlg} 3$ and 4) has been associated with ASDs in humans and impaired social and communication behavior in mice. Making use of a set of behavioral and social assays, we, here, analyzed the impact of two Drosophila Nlgs, Dnlg2 and Dnlg4, which are differentially expressed at excitatory and inhibitory central nervous synapses, respectively. Both Nlgs seem to be associated with diurnal activity and social behavior. Even though deficiencies in Dnlg2 and Dnlg4 appeared to have no effects on sensory or motor systems, they differentially impacted on social interactions, suggesting that social behavior is distinctly regulated by these Nlgs.

Keywords: Drosophila melanogaster, social behavior, activity monitoring, interindividual distance, sensory-motor functions, mutations, human neuro-developmental diseases

\section{INTRODUCTION}

Molecular mechanisms that regulate cellular metabolism, development, differentiation, and survival are essentially shared by most animal species. Recent evidence suggests that the last common ancestor of vertebrates and invertebrates, the so-called urbilaterian, already possessed a centralized nervous system that contained the precursors of brain structures and neurosecretory organs of extant protostomes and deuterostomes $(1,2)$. In this respect, homologous structures have been identified between insect and mammalian brains, such as the mushroom bodies and the pallium or cortex (2), the central complex and the basal ganglia (3), the pars intercerebralis/pars lateralis/corpora cardiaca system and the hypothalamus-pituitary axis $(4,5)$, the corpora allata, and the adenohypophysis (anterior pituitary) (6). Moreover, genes implicated in human disease and the generation of social behaviors have well-conserved homologs in insects and other invertebrates (7-9).

Studies on the fruit fly, Drosophila melanogaster, have successfully contributed to the characterization of molecular pathways underlying human nervous system diseases, such as Rett syndrome, Parkinson's disease, Alzheimer's disease, and others (10-13). More recently, 
Drosophila has even been used to study the mechanistic basis of neuro-developmental diseases, such as fragile $\mathrm{X}$ syndrome $(14,15)$, autism spectrum disorders (ASDs) (16), and schizophrenia (17-19).

Drosophila may serve as a suitable organism to study the basis of these diseases since it performs elaborate social interactions, such as courtship $(20,21)$ and aggression with the establishment of social dominance $(22,23)$, uses intraspecific acoustic communication (24), establishes long-term memory in classical and operant learning paradigms (25), and performs sensory-motor tasks with great precision (26). Drosophila offers molecular and genetic tools to identify the functions of individual genes and proteins, their interaction partners within cellular/molecular pathways [recent summary (27)], and their impact on physiology and behavioral performance. Homologs of disease-related genes can be mutated globally or in particular tissues or cell types, and transgenic flies may express human genes with or without characteristically disease-related mutations. Whether, and how, such genetic alterations impact Drosophila social behavior needs to be assessed in a quantifiable manner.

Neuroligins (Nlgs) are postsynaptic adhesion molecules that typically associate with presynaptic neurexins to form bidirectional signaling complexes required for the correct formation, maturation, and functional adjustment of chemical synaptic connections between neurons (28-31). Additional neurexinindependent synaptic functions have also been reported [reviewed by Reissner et al. (32)]. In mammalian nervous systems, different Nlgs are differentially expressed at different types of synapses [reviewed in Ref. (33-35)]. Nlg1 is predominantly expressed at excitatory glutamatergic synapses, fostering the accumulation of postsynaptic density proteins and ionotropic and metabotropic glutamate receptors (36). Nlg2 is selectively expressed at inhibitory synapses, where it associates with gephyrin and recruits GABA or glycine receptors (37). Nlg3 and Nlg4 appear at both excitatory and inhibitory synapses with preferences of Nlg3 for GABAergic and Nlg4 for glycinergic synapses (38-42). Alterations in $n l g$ genes were found in patients affected by ASDs (40-43) and mutations of the same genes caused autism-like phenotypes in rodent model organisms $(35,44)$. ASD represent neuro-developmental disorders that cause impairments in social interaction and communication accompanied by restricted and repetitive behaviors. Especially mutations in $n \lg 3$ and $n \lg 4$, mutations in genes encoding direct interaction partners of Nlgs, such as neurexins and shank, and alterations of other proteins involved in synaptic mechanisms are directly associated with ASD (44-46). Based on the differential expression of Nlgs at different types of synapses, it was hypothesized that ASD phenotypes may result from disturbed balance of excitatory and inhibitory synaptic transmission in brain regions controlling respective behaviors and functions (47). Supporting evidence for this hypothesis derived from both ASD patients [review by Dickinson et al. (48)] and studies on rodent models for ASD (46, 49-52).

Much like in mammals, insects present multiple neuroligin genes (38), whereby the four genes found in D. melanogaster (nlg1-nlg4) show differential expression at central and peripheral nervous synapses. None of these genes has a particular similarity to the four mammalian $n l g$ genes and the designations (vertebrate $n \lg 1-4$ vs Drosophila $n \lg 1-4)$ do not imply phylogenetic relatedness. Previous studies have shown that Dnlg2 is predominantly expressed by excitatory postsynapses (53), while Dnlg4 is abundant at inhibitory synapses (54). Immunostaining with a Dnlg2 antibody in the adult Drosophila brain shows that the protein is abundant in the mushroom body and the central complex (W. Xie, personal communication). Both these brain structures are involved in the control of diverse behaviors like short-term courtship memory, center avoidance, olfactory learning, sleep regulation, and spatial orientation (55-59). Antibody staining against Dnlg4 revealed high expression in the lateral clock neurons (LNvs), possibly explaining the abnormal sleep behavior found in dnlg4-mutant flies, as well as expression in the central complex (54). Earlier studies (16) revealed that deletion of the $d n \lg 2$ gene alters social behavior in Drosophila. While retaining intact sensory perception, Dnlg2-deficient flies display reduced social interactions with respect to male-female courtship and male-male agonistic behavior, produce altered acoustic communication signals, and often fail to terminate behavior upon context changes. In the present study, we subjected flies deficient in Dnlg2 (typically expressed at excitatory synapses) or Dnlg4 (typically expressed at inhibitory synapses) and wild-type D. melanogaster (wt) to a series of behavioral assays that assess their social interactions (courtship, aggression, group formation, reaction to conspecific songs) and, in addition, analyzed their acoustic communication signals. We also tested for motor and sensory defects by analyzing locomotion, open space avoidance, circadian activity, and the sound sensitivity or their hearing organs. Our results show that both Dnlg2 and Dnlg4 are implicated in Drosophila social behavior.

\section{MATERIALS AND METHODS}

\section{Animals}

All flies were reared at $25^{\circ} \mathrm{C}$ temperature with $60 \%$ humidity under a 12:12-h dark/light cycle and on standard medium, which was made from $500 \mathrm{~g}$ fresh yeast, $500 \mathrm{~g}$ sugar, $20 \mathrm{~g}$ salt, $60 \mathrm{~g}$ agarose, $250 \mathrm{~g}$ flour, $1 \mathrm{l}$ conventional apple juice (Alnatura, Bickenbach, Germany), and $30 \mathrm{ml}$ propionic acid. Water was added so that the medium would amount to 71 . Studies were performed with the Dnlg2-deficient mutant line $d n \lg 2^{\mathrm{KO} 17}$ (provided by Wei Xie, Southeast University, Nanjing, China), generated by targeted knockout of the dnlg2 genomic locus (53). Studies with a second Dnlg2-deficient line $\left[\operatorname{dnlg} 2^{\mathrm{KO} 0} ;(53)\right]$ that was tested in some of the assays generated qualitatively similar results. The Dnlg4-deficient mutant line was generated by crossing a $d n \lg 4^{\text {del }}$ (54) deletion and a $d n \lg 4$ point mutation $\left(d n \lg 4^{L L 01874}\right)$ line (both provided by Junhai Han, Southeast University, Nanjing, China) (54), as both of them are homozygously lethal. We note that both fly lines are hypomorphs and still express limited amounts of the respective Nlg (less than 30\% compared to wild type). Canton-S was used as wild-type control, and all mutant lines were kept as "Cantonized" lab stocks (dngl2-mutants were outcrossed for six generations in-house; dnlg4-mutants were obtained as outcrossed). Unless otherwise stated, flies were tested at the age of 5-7 days. 


\section{qRTPCR}

RNA was isolated from 50 fly heads per strain ( $\ln \lg 4^{L L 01874 / D e f}$, $d n \lg 2^{K O 17}$, Canton-S, $w^{1118}$; resulting in a total of 200 heads) using the "ZR Tissue and Insect RNA MicroPrep" Kit (Zymo Research Europe GmbH, Freiburg, Germany; \#R2030). 1 gg RNA per sample was reversely transcribed to cDNA via the "QuantiTect Rev. Transcription Kit” (Qiagen, Valencia, CA, USA, Cat No./ ID: 205311) for primer sequences $(10 \mathrm{pmol} / \mu \mathrm{l})$, see Table S2 in Supplementary Material. Three repetitions were run for each strain, with $10 \mathrm{ng}$ of the respective cDNA diluted in $4 \mu \mathrm{l}$ of water. We added $5 \mu$ of SYBR Green (iQ ${ }^{\mathrm{TM}}$ SYBR ${ }^{\circledR}$ Green Supermix $2 \times$, Bio-Rad Laboratories GmbH, Munich Germany; \#1708880) and $1 \mu \mathrm{H}_{2} \mathrm{O}$ containing $0.1 \mu \mathrm{l}$ of the forward and backward primers. The total 10 sample were sealed with transparent wrapper foil and centrifuged for $2 \mathrm{~min}$ at 2,000 rpm. RT-qPCR was performed on a Bio-Rad MyiQ Single color RT PCR Cycler (Bio-Rad Laboratories $\mathrm{GmbH}$, Munich, Germany) employing the following program cycle: $3 \mathrm{~min} 95^{\circ} \mathrm{C}, 10 \mathrm{~s} 95^{\circ} \mathrm{C}, 30 \mathrm{~s} 60^{\circ} \mathrm{C}$, and $30 \mathrm{~s} 72^{\circ} \mathrm{C}$. The cycles were repeated 40 times. We used Rpl32 as a reference gene for cDNA concentration.

\section{Acquisition and Analysis of Locomotion Data}

Flies $\left[N(w t)=97, N\left(\operatorname{dnlg} 2^{K O 17}\right)=96, N\left(\operatorname{dnlg} 4^{\text {del/LL01874 }}\right)=66\right]$ were transferred individually in a circular arena of $40-\mathrm{mm}$ diameter filled with $1 \%$ agarose $/ 1 \%$ glucose and closed with an anti-glare Perspex plate. A distance of $2 \mathrm{~mm}$ between pane and medium allowed the flies to walk freely but prevented them from flying (see Figures 1A,C). The arena was produced using an Ultimaker 3D printer (Ultimaking Ltd., Geldermalsen, Netherlands) and movies were recorded using TroublePix software (NorPix Inc., Montreal, QC, Canada) and a MotionTraveller 500 camera (IS, Imaging Solutions $\mathrm{GmbH}$, Eningen, Germany) at 500 frames per second (fps). The flies were illuminated from below with infrared LEDs (Pollin Electronic GmbH, Pförringen, Germany; \#531090). Full LED illumination caused a temperature increase of ca. $0.01^{\circ} \mathrm{C}$ per minute. Because animals were allowed to spend maximally $5 \mathrm{~min}$ in the arena, the corresponding temperature change they experienced during their stay was ca. $0.05^{\circ} \mathrm{C}$. Post hoc analysis of the video footage was performed using ivTools (Dr. Jens P. Lindemann; Bielefeld University) to acquire walking trajectories.

To deduce fly-based velocity combinations from the trajectory, we used unsupervised $\mathrm{k}$-means clustering to classify data points into a set of " $k$ " clusters (60). The fkmeans function for Matlab authored by Tim Benham was used. ${ }^{1}$

\section{Probability Density in a Circular Arena}

Animals were set in the middle of a circular arena $40 \mathrm{~mm}$ in diameter (see Figure 1A and previous paragraph). Each animal was recorded for $10 \mathrm{~s}$ of consecutive walking to exclude effects caused by resting. To obtain probability densities, the Cartesian

${ }^{1}$ https://de.mathworks.com/matlabcentral/fileexchange/31274-fast-k-means.
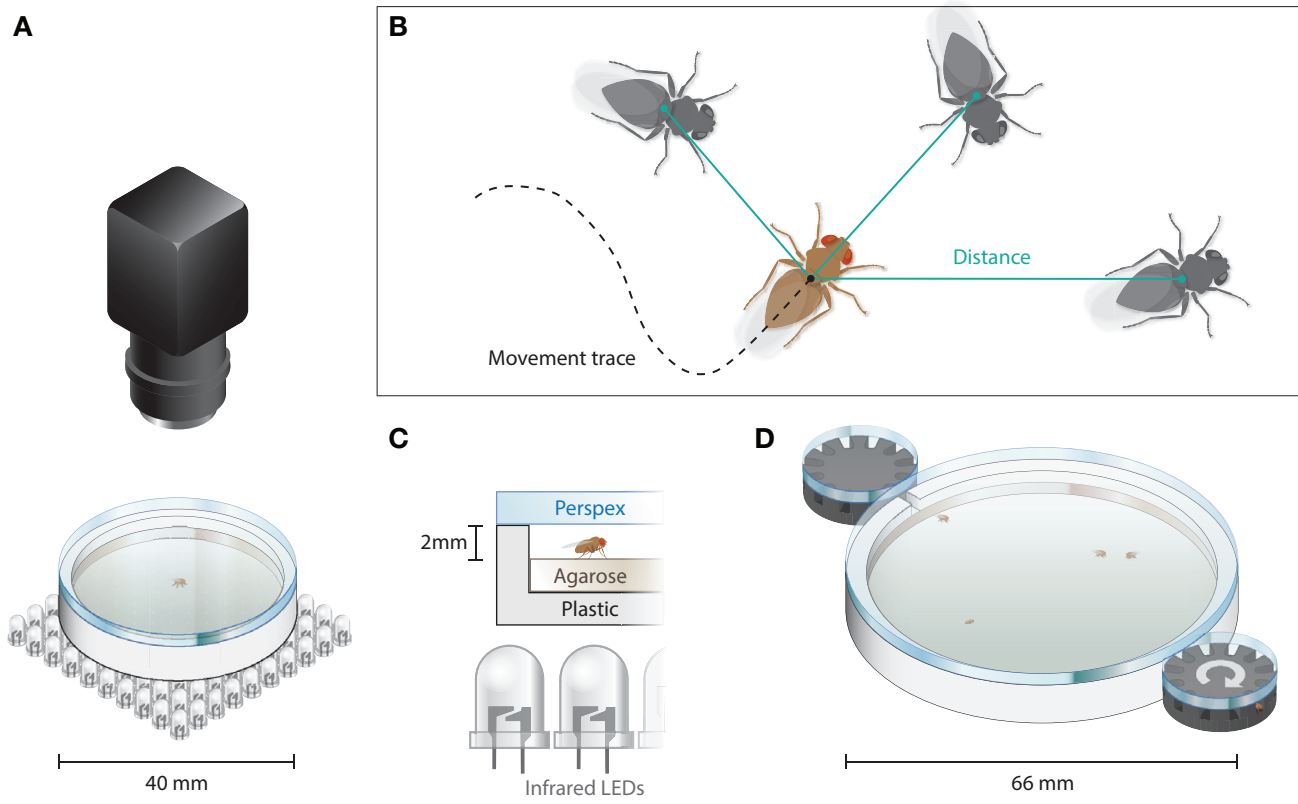

C

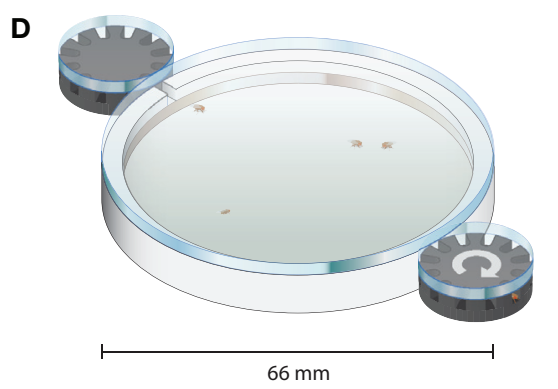

FIGURE 1 | Data acquisition for locomotion and positional data. (A) Sketch of the walking arena used to assay locomotion and center avoidances [zoom-in in (C)]. Shadows of the flies were projected via a field of LEDs below the arena onto the camera. Visible light sources placed in the proximity (B). Trajectories of individual flies were derived via the detection of ellipses (Drosophila body) in the difference image. Individual positions were used to determine interindividual distances between flies. (C) Close-up of the setup including the anti-glare Perspex pane, which was coated with Sigma-Aldrich Sigma Cote from the lower side, preventing the animal from crawling on the ceiling. (D) Social interaction arena, in which 24 flies were released one by one. The flies were released from the black revolvers, which are connected by a little tunnel to the main arena and hold 12 animals each. Every $90 \mathrm{~s}$, one of the two revolvers would turn to release one fly. 
coordinates $x$ and $y$, which were acquired through trajectory tracing, were transformed into polar coordinates with polar angle $\theta$ and radius $r$. We calculated the histogram of $r$ for each fly and the median histogram for each strain, respectively. We then normalized that histogram for the surface area of each bin and normalized the resulting histogram so that its integral is 1 , providing a probability density.

We also analyzed the median radius position by calculating the median $r$ of each individual fly. The statistical difference between fly lines was calculated using a two-sided KolmogorovSmirnov test. $p$-Values were corrected via the BenjaminiHochberg false discovery rate procedure (see Statistical Analysis).

\section{Circadian Rhythm}

Circadian rhythm was analyzed using the Drosophila Activity Monitoring (Tritech Research, CircKinetics ${ }^{2}$ ) System. Flies were placed individually in glass tubes (diameter $3 \mathrm{~mm}$; length $7 \mathrm{~cm}$ ) and sealed with a gas permeable cap on one side and standard food on the other side. The food medium was identical to the rearing medium described before. The tubes were inserted into an incubator with a 12:12-h dark/light cycle, matching that of fly breeding incubator. Crossings of the midline were detected as interruptions of an infrared light beam and were automatically counted for 7 days. The first $48 \mathrm{~h}$ were omitted to avoid differences in behavior due to the relocation of the animal.

\section{Analysis of Social Distance and Group Behavior}

Flies $\left[N(w t)=104, N\left(\operatorname{dnlg} 2^{\text {KO17 }}\right)=94, N\left(d n \lg 4^{\text {del/LL01874 }}\right)=119\right]$ were allowed to enter a circular aluminum walking arena of 66-mm diameter through two entrances on opposite sides (see Figure 1D). The arena was illuminated from below with LEDs (Nichia Cooperation, Tokushima, Japan; \#NSSW157AT-H3). Each entrance was connected to a 12-chamber rotating revolver loaded with a single fly per chamber, allowing one fly at a time to enter the arena every $90 \mathrm{~s}$. The positions of individual flies were determined at a frame rate of $50 \mathrm{fps}$, and the trajectories were analyzed afterward with ivTools (see Acquisition and Analysis of Locomotion Data).

To associate individual flies with a group, we used agglomerative hierarchical clustering. This algorithm uses the Euclidian distance between individual flies to determine their incorporation in a group. The agglomerative clustering runs showed a clear threshold at about $20 \mathrm{~mm}$ interindividual distance and, accordingly, animals being more than $20 \mathrm{~mm}$ away from the next fly were counted as not being part of a group. At this distance, a Drosophila fly extends the visual field of only one ommatidium (61). Only flies that gathered together for more than $30 \mathrm{~s}$ were counted as groups.

Male-male courtship and the formation of chains of multiple males following each other were scored from the videos by eye. The latter chaining behavior was only taken into consideration when a male followed another one with its wing extended for more than $3 \mathrm{~s}$ (most chains were stable for several minutes). The leading animal was not considered to be actively chaining and was, therefore, excluded. An example of chaining behavior can be seen in Figure S1A in Supplementary Material.

\section{Peripheral Auditory Functions}

To test for possible defects in hearing, we affixed the flies with wax on a focus holder (62) and then measured vibrations of their antennal sound receiver (63).

Vibrations were measured at the tip of the antennal arista using a PSV-400 Laser-Doppler-Vibrometer (Polytec GmbH, Waldbronn, Germany). For acoustic stimulation, pure tones were broadcasted via a loudspeaker positioned $\mathrm{ca} .10 \mathrm{~cm}$ behind the fly. The stimulus frequency was adjusted to match the individual best frequency of the fly's receiver as determined from the power spectrum of its vibrations in the absence of sound (64). Electrophysiological recordings of compound action potentials of auditory receptor neurons were performed with an etched tungsten electrode inserted between antenna and head (65).

\section{Sound Recordings}

Male courtship songs (CSs) in the presence of a decapitated, 5- to 7 -day-old virgin female were recorded using a microphone (Bruel \& Kjaer Type 4165) in a soundproof chamber. The recorded signals were amplified, band bass filtered $(70-5,000 \mathrm{~Hz})$, and directly digitized with a sampling frequency of $44,100 \mathrm{~Hz}$. For acquisition, Audacity 2.0.6 ${ }^{3}$ was used. Analysis was done using custom made MatLab programs. To determine the dominant frequency components of the songs, Fast Fourier Transformation using a 4096 Hanning window was applied.

\section{Competitive Courtship Assay with Acoustic Stimulation}

Competitive courtship assays were performed with two socially naïve males (age 7-12 days) placed together with a decapitated, 5to 7-day-old, virgin wt female in a circular arena with $2 \mathrm{~cm}$ diameter. The age disparity in male flies should have limited effects on the mating behavior, in this case. As the female is decapitated and mating is never successful, the attractiveness of males does not influence the female's choice as described for different male age groups $(66,67)$. The initiation of courtship by the male does not vary much between the 7 th and 14 th day of age (68). The bottom of the arena consisted of a fine mesh. During the experiments, flies were exposed to either white noise (WN), aggression songs (AS), or CSs that were previously recorded from wild-type males (69). Acoustic stimuli were presented by a loudspeaker situated below the arena. Videos of the experiments were recorded for 15 min with a frame rate of 30 fps. Only the periods from 5 to 10 min after start of the experiments were considered.

Frame-by-frame analysis of recorded videos was performed by an observer unaware of stimulus conditions and fly strain. For each frame either idle, unilateral wing extension as a hallmark of courtship or aggression behavior was allocated to the acting individual fly. This was done using an in-house developed software tool that allows for fast video annotation via a game pad. This 
system allowed for long scoring sessions and high throughput via the observers, who scored 9,000 frames per replicate. Aggressive behavior directed against the other male was recognized by aggressive acts like boxing, leg kicking (see Figure 7), and production of agonistic sound signals with both wings elevated. Courtship behavior toward the female was identified by unilateral wing extension associated with the production of CSs or clear copulation attempts with the abdomen. From the total duration of courtship $\left(D_{\mathrm{C}}\right)$ and aggression $\left(D_{\mathrm{A}}\right)$ we calculated a behavioral contrast $(c)$ :

$$
c=\frac{D_{\mathrm{A}}-D_{\mathrm{C}}}{D_{\mathrm{A}}+D_{\mathrm{C}}}
$$

Positive $c$ values indicate that the male spent more time with aggression, while negative values denote that the animal spent more time with courtship.

\section{Software Tools}

All presented calculations were done in MATLAB R201 (The MathWorks Inc., Natick, MA, USA) running on a Java 1.6.0_17b04 system (Sun Microsystems Inc.). The following toolboxes were used: MATLAB (Version 8.0), Simulink (Version 8.0), Box Counting (Version 1.10), Curve Fitting Toolbox (Version 3.3), Image Processing Toolbox (Version 8.1), Signal Processing Toolbox (Version 6.18), and Statistics Toolbox (Version 8.1). Video Annotation software was developed on Python 2.7.11 employing the pygame site package. ${ }^{5}$

\section{Statistical Analysis}

To test for significant differences between experimental groups, Fisher's permutation test was applied to evaluate the differences of the medians of the respective measured variables. In some cases, we used a two-sided Kolmogorov-Simrnov test and once Fisher's exact test (instances are indicated). $p$-Values were always corrected using the Benjamini-Hochberg false detection rate (71) procedure by applying the Matlab implementation of David M. Groppe. ${ }^{6}$

\section{RESULTS}

Heads of 50 Dnlg2-deficient and 50 Dnlg4-deficient flies were subjected to qPCR, revealing reduced levels of the respective dlng transcripts by 27 and $40 \%$ compared to wild type (see Table S1 in Supplementary Material), respectively. We subjected these flies to various tests to assess their behaviors. To identify general defects in mobility, we first monitored their spontaneous locomotion in a plain, circular arena. The locomotion trajectories were categorized using unsupervised k-means clustering as reported in Ref. $(71,72)$. The resulting movement categories were two "forward-sideways movements," two "fast yaw turns," and "resting" [see also Ref. (61)]. The distribution of these three categories showed no significant differences between wild type and the two mutant stains (Figure 2). Therefore, locomotion and its assembly

\footnotetext{
${ }^{4}$ www.python.org.

${ }^{5}$ www.pygame.org.

${ }^{6}$ https://de.mathworks.com/matlabcentral/fileexchange/27418-fdr-bh.
}

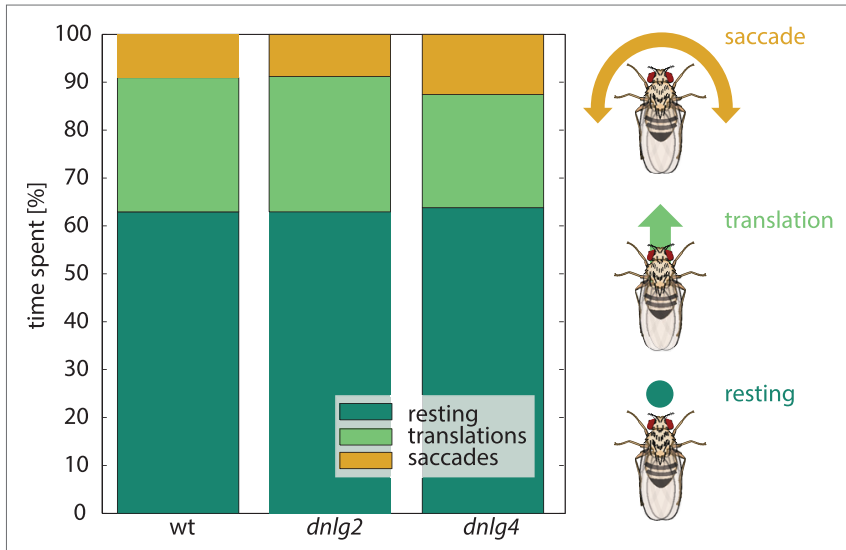

FIGURE 2 | Locomotion. Distribution of the three fly-based velocity vectors representing a rotational movement, translation (forward movement), and resting, obtained by unsupervised k-means clustering [see Materials and Methods; (70)]. Colored boxes indicate the percentage of time spent with the respective behavior. Wild-type (wt) and Dnlg2-deficient flies spent equal times with the three behaviors. Dnlg4-deficient flies perform slightly less translation movements, though this effect is not significant $[N(w t)=97, N($ dnlg2 $)=96$, $N(\mathrm{dn} \lg 4)=66]$

from movement components seemed to be uncompromised by mutations in $d \operatorname{lng} 2$ and $d \operatorname{lng} 4$ and mutant defects in other behaviors are unlikely to result from general locomotion impairments.

The avoidance of central (open) areas of an arena is called centrophobia $(73,74)$. In Drosophila, impaired centrophobia has been associated with defects of the mushroom bodies (55). In contrast to wild-type flies that nearly exclusively circled around the edge of the arena, both $d n l g$-mutants often traversed the central part of the arena (Figure 3). Both mutant strains seemed to avoid the immediate vicinity of the walls, resulting in median radial positions that are significantly closer to the center than in $w t$ (Figure 3B, two-sided Kolmogorov-Smirnov test $p>0.01$ ). Dnlg4-deficient flies even displayed a weak tendency for preferred occupation of central regions.

A previous study demonstrated alterations of sleep in $d n l-$ $g 4^{\text {LL01874/Def-mutant flies (54). We, thus, analyzed activity patterns }}$ and found Dnlg4-deficient flies have longer, but fewer episodes of sleep compared to wild-type and Dnlg2-deficient flies (see Figures 4D,E). Dnlg2-deficient flies, however, seemed to show an opposite phenotype with more but shorter sleep episodes than the wild type. Wild-type and both Dnlg-deficient fly strains displayed activity peaks associated with, or slightly preceding, the dark-to-light and light-to-dark switches (Figure 4A). In $d n \lg 4^{L L 01874 / D e f}$, these peaks lasted longer than in wild type and $d n \lg 2^{\mathrm{KO} 17}$-mutants (Figure 4A); their overall activity was significantly reduced compared to both other strains during light periods (Figure 4B) and compared to wt during dark periods (Figure 4C). Compared to wt, Dnlg2-deficient flies displayed a slight but not significant increase of center crossing activity during light phases (Figure 4B) and no difference during dark periods (Figure 4C). In summary, overall activity is reduced in $d n \lg 4^{L L 01874 / D e f}$ flies compared to wild-type flies (Fisher's permutation test corrected with Benjamini-Hochberg fdr; $p$-value 


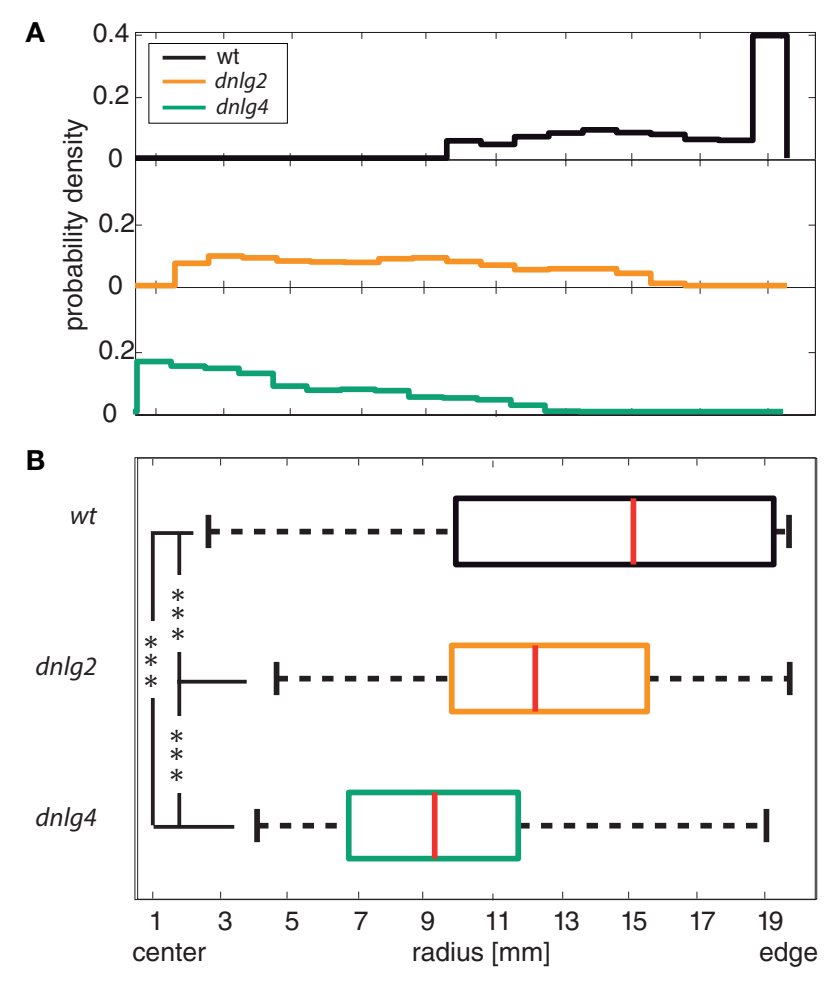

FIGURE 3 | Center avoidance. (A) Histogram of the probability density within a circular arena for wild-type (wt), Dnlg2-deficient (dnlg2 $\left.{ }^{K O 17}\right)$, and Dnlg4-

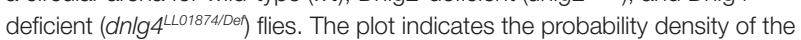
three fly lines in dependence to the position in the arena. $0 \mathrm{~mm}$ on the $y$-axis corresponds to the center of the arena; $20 \mathrm{~mm}$ corresponds to the edge of the arena. Wt shows a highly preferred presence at the edge of the arena and an avoidance of the center region. Dnlg2 and $d n \lg 4^{L L 01874 / D e f}$ all display increased presence in central regions of the arena and a diminished probability density closer to the edge. (B) Boxplot of the median radius position of each individual. Red lines in box plots indicate the medians; boxes include $50 \%$ of the data set around the medians; whiskers include $1.5^{\star}$ interquartile distance and outliers are marked with red crosses (not shown). The median position is shifted significantly to the center of the arena in comparison to the wild type. We used a two-sample Kolmogorov-Smirnov test and corrected $p$-values via the Benjamini-Hochberg false FDR [p-values: wt vs $d n / g 2^{\text {KO17 }} 1.4845 \times 10^{-4}$; $w t$ vs dngl4 $3.0372 \times 10^{-7} ;$ dnlg2 $2^{K O 17}$ vs dngl4 1.1854e $\times 10^{-4} ; N(w t)=97$, $\left.N\left(d n \lg 2^{K 017}\right)=96, N\left(d n \lg 4^{\text {LLO1874/Def }}\right)=66\right]$.

$0.00015)$ and $d n \lg 2(p=0.00008)$, while $d n \lg 2^{K O 17}$ flies show a tendency for increased activity that fails significance $(p=0.09102)$ at least during periods of light.

Previously, Dnlg2-deficient flies reportedly displayed abnormal social and mating behavior (16). In order to study altered attraction to conspecifics, we recorded the location data of 24 animals (per replicate) that were allowed to successively enter a circular arena from two opposite sides in 90-s intervals. To assess group formation, we used their positional data and subjected it to a hierarchical agglomerative clustering. While wild-type males remained single with a probability of $39 \%$, this probability was significantly increased in Dnlg2-deficient flies (60\%) and reduced to $24 \%$ in Dnlg4-deficient flies [Figure 5C; Fisher's exact test $p$-value $w t$ vs $d n \lg 2^{K O 17}=0.0065 ; w t$ vs $d n \lg 4^{L L 01874 / D e f} p=0.0304$; $d n \lg 2^{\text {KO17 }}$ vs $d n \lg 4^{\text {LL01874/Def }} p=5.6103 \times 10^{-7} ; N(w t)=104$, $\left.N\left(d n l g 2^{\text {KO17 }}\right)=94, N\left(\operatorname{dnlg} 4^{L L 01874 / D e f}\right)=119\right]$. Wild-type flies and $d n \lg 2^{\mathrm{KO} 17}$-mutants associated in groups of up to seven individuals whereas group size shifted to larger values in $d n \lg 4^{\text {LL01874/Def }}$ mutants with up to 15 animals per group [Figure 5A; differences in group sizes tested with a two-sided Kolmogorov-Smirnov test ( wt vs $d n \lg 2^{\text {KO17 }} p=0.0198 ; w t$ vs $d n \lg 4^{L L 01874 / \text { Def }} p=3.2577 \times 10^{-4}$; $d n \lg 2^{\text {KO17 }}$ vs $d n \lg 4^{\text {LL01874/Def }} p=2.5584 \times 10^{-9} ; N(w t)=104$, $N\left(d n \lg 2^{\text {KO17 }}\right)=94, N\left(\operatorname{dnlg} 4^{L L 01874 / D e f}\right)=119 ; p$-values corrected after (70))]. Chaining behavior was excluded from this analysis, because this phenomenon was caused by an improper termination of courtship and not a direct effect on aggregation behavior. We also calculated the average distances of animals to their nearest neighbor within such groups. Compared to wild-type and $d n \lg 2^{\mathrm{KO} 17}$-mutant males that maintained similar interindividual distances, the distance was reduced in Dnlg4-deficient flies (Figure 5D). Hence, although interindividual distances are only changed in $d n l g 4^{L L 01874 / D e f}$-mutants, Dnlg2-deficient males have a lower tendency to form groups, while $d n \lg 4^{\text {LL01874/Def }}$ mutants show an increased tendency to aggregate (Figure 5B).

Courting D. melanogaster produce two types of songs, a sine song and a pulse song. These acoustic communication signals play important roles in driving female mating decisions. By comparing songs between the three strains, we found that mutations in both $d n \lg 2^{K O 17}$ and $d n \lg 4^{L L 01874 / D e f}$ affect the songs. The major frequency component of sine songs was quite variable in wild type, ranging between 120 and $160 \mathrm{~Hz}$ (Figure 6B). While the dominant sine song frequency was slightly lowered in Dnlg2-deficient flies, Dnlg4-deficient flies produced songs with higher sine song frequencies $\left(d n \lg 2^{\text {KO17 }}\right.$ vs $d n \lg 4^{L L 01874 / D e f} p=0.00625$; Fisher's permutation test, corrected by Benjamini-Hochberg fdr). Analysis of courtship pulse songs revealed no differences in amplitude and shape (number of oscillations per pulse) between wild-type males and the two $d n \lg$-mutants, suggesting that the neuromuscular components that generate acoustic communication signals were not compromised by the mutations in Dnlgs. Interpulse intervals had median durations of $38 \mathrm{~ms}$ in wild types and $37 \mathrm{~ms}$ in $d n \lg 4^{\text {LL01874/Def }}$ but were significantly longer in CSs of $d n \lg 2^{\mathrm{KO} 17}$-mutants (Figure 6C).

We, next, analyzed male-chaining behavior, whereby males follow each other with one extended wing (75). The probability of wild-type males to engage in male-directed courtship was generally low and remained below 5\% even when the arena was filled with larger numbers of individuals (Figures 6D,E). Chaining, however, was entirely absent in Dnlg2-deficient flies and thereby significantly lower compared to wt ( $p$-value $>0.001$; KolmogorvSmirnov). In contrast, $d n \lg 4$-mutants formed courtship chains that included up to 17 animals, and the probability of individual flies to engage in chaining increased significantly ( $p$-value $>0.001$; Kolmogorv-Smirnov), reaching more than $60 \%$ as the number of animals in the arena was increasing (Figure 6D). In summary, absence of Dnlg2 and Dnlg4 not only affects male CSs, but also chain formation, a male-directed courtship behavior.

Hahn et al. (16) reported reduced social interactions in Dnlg2deficient flies in competitive courtship assays where two males switched between male-directed agonistic and female-directed behavior. A recent study (76) further reported that AS promote aggression, while CSs inhibit aggressive interactions between Drosophila males. In order to test whether Dnlg2- and Dnlg4deficient flies react appropriately to sound signals, we extended 

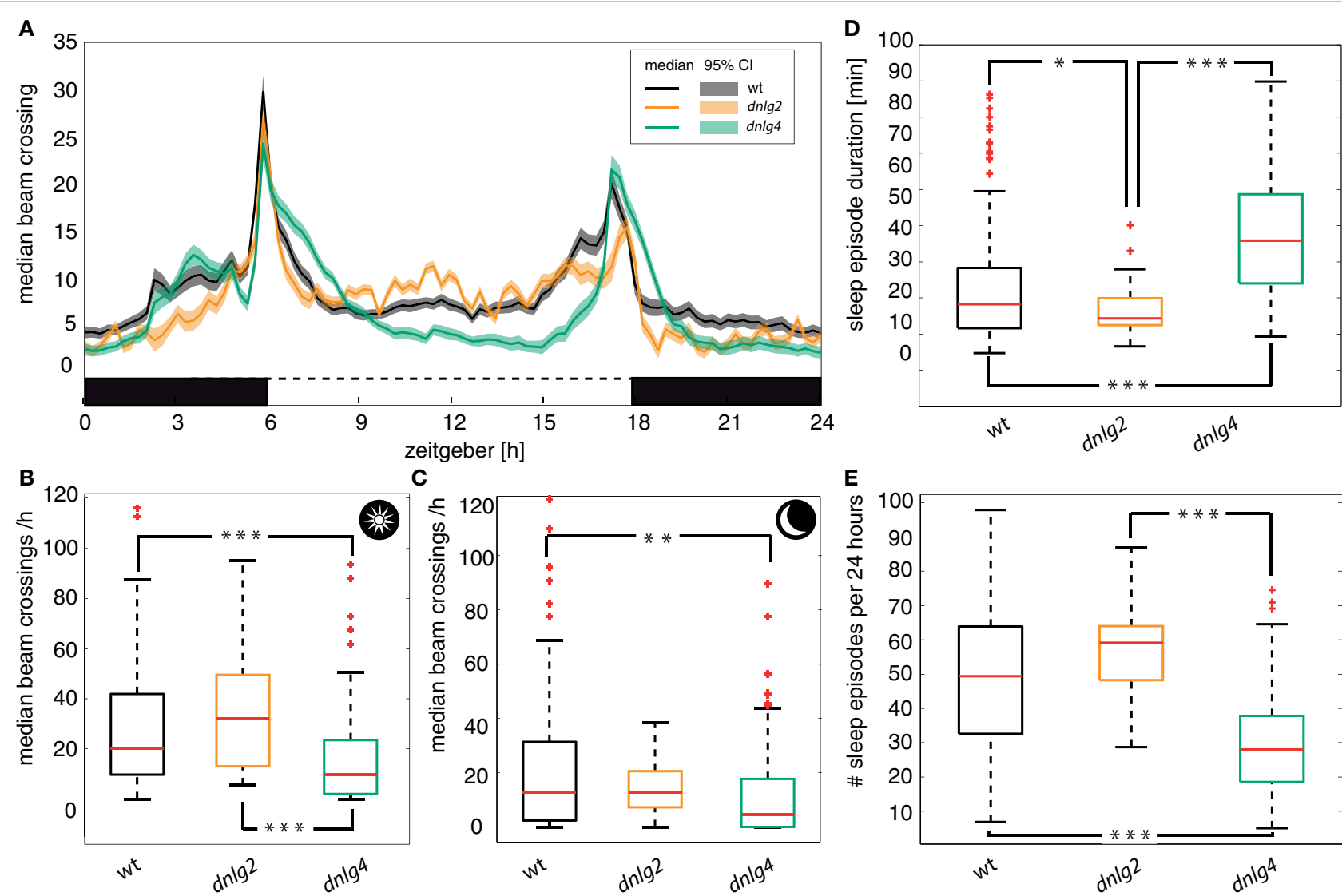

FIGURE 4 | Circadian activity. (A) Average number of beam crossings of male flies during 5 days in a 12:12-h dark/light cycle. Boxes: black = dark, white = light. Solid lines: median; shaded areas: 95\% confidence interval of the median. All genotypes show increased activity coinciding with dark/light and light/dark changes. The activity phases around the dark/light and light/dark changes are broadened or shifted in dnlg4 ${ }^{L L 01874 / D e f}$-mutant flies. (B) Diurnal activity based on the median number of beam crossings per hour. Panels $(\mathbf{B}, \mathbf{C})$ include data of the 10-h period around noon or midnight, respectively, excluding the hours with light changes and activity peaks. (D) Median duration of a sleep episode. A sleep episode was defined by the absence of beam crossings in a time window of 5 min. Dnlg2-deficient flies have significant lower sleep duration compared to wt (Kolmogorov-Smirnov Test corrected by Benjamini-Hochberg $p=0.0269$ ) or Dnlg4-deficient flies $\left(p=9.54 \times 10^{-8}\right)$. The Dnlg-4-deficient flies sleep duration even surpasses that of the wt $\left(p=4.1 \times 10^{-13}\right)$. (E) Number of sleep episodes in a $24-h$ cycle. Dnlg4deficient flies show less sleep episodes that the wild type (wt vs $d n \lg 4^{\text {LL01874/Def }} p=1.51 \times 10^{-12} ; d n \lg 2^{\text {KO17 }}$ vs $d n l g 4^{\text {LLO1874/Def }} p=8.84 \times 10^{-7}$ ). Dnlg2-deficient flies just miss significance at a $p$-value of 0.065

the competitive courtship paradigm by continuous stimulation with WN, CS, or aggression sounds. Prior to the experiments, we assayed hearing organ function in the flies, revealing that auditory mechanics and sound-induced auditory nerve response in both mutant strains resemble those of wild-type flies (Figure 6A). During stimulation with WN and CSs $w t$ males spent more time courting the female than displaying aggression against the other male (see Figure 7). During stimulation with aggression sounds, the latter male-directed aggression was increased [Figure 7A; Fisher's exact test corrected with Benjamini-Hochberg fdr; $p$-value $w t$ (white noise) vs $w t$ (aggression sounds) $=0.0237$ ] Neither Dnlg2- or Dnlg4-deficient males altered the frequencies of aggressive and courtship behavior during stimulation with aggressive sounds. Stimulation with CSs slightly increased wt courtship behavior, whereas the opposite effect was seen in Dnlg2- and Dnlg4-deficient males, which reduced their courtship significantly and increased aggression ( $w t$ vs $d n \lg 2^{\text {KOII }} p=0.0237$; $w t$ vs $\left.d n l g 4^{L L 01874 / D e f} p=0.0237\right)$. Hence, both Dnlg2- and Dnlg4deficient flies seem to fail to respond appropriately to sounds.

\section{DISCUSSION}

The presented behavioral data suggest that the trans-synaptic adhesion molecules Dnlg2 and Dnlg4 may play a prominent role in the neuronal regulation of Drosophila's social interactions. $d n \lg 2$ and $d n \lg 4$ are both expressed at central nervous synapses, but Dnlg2 is also present at neuromuscular synapses (53). Of the other two Drosophila Nlgs, $d n \lg 1$ is expressed at neuromuscular postsynapses (77) and $d n \lg 3$ is expressed in neuromuscular junctions and the central nervous system (78). Similar to Nlgs in mammalian central nervous systems, Dnlg1, Dnlg2, and Dnlg3 seem important for synaptic maturation and functional maintenance (studied at the neuromuscular junction) rather than being crucial for synaptogenesis. 

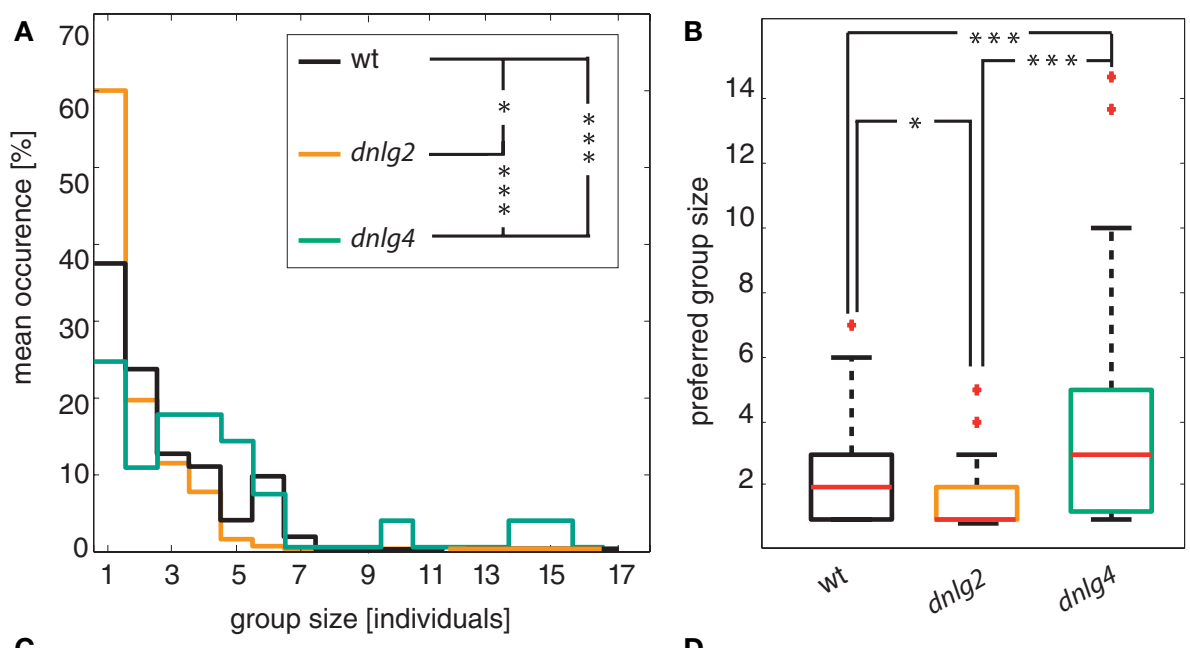

C

D
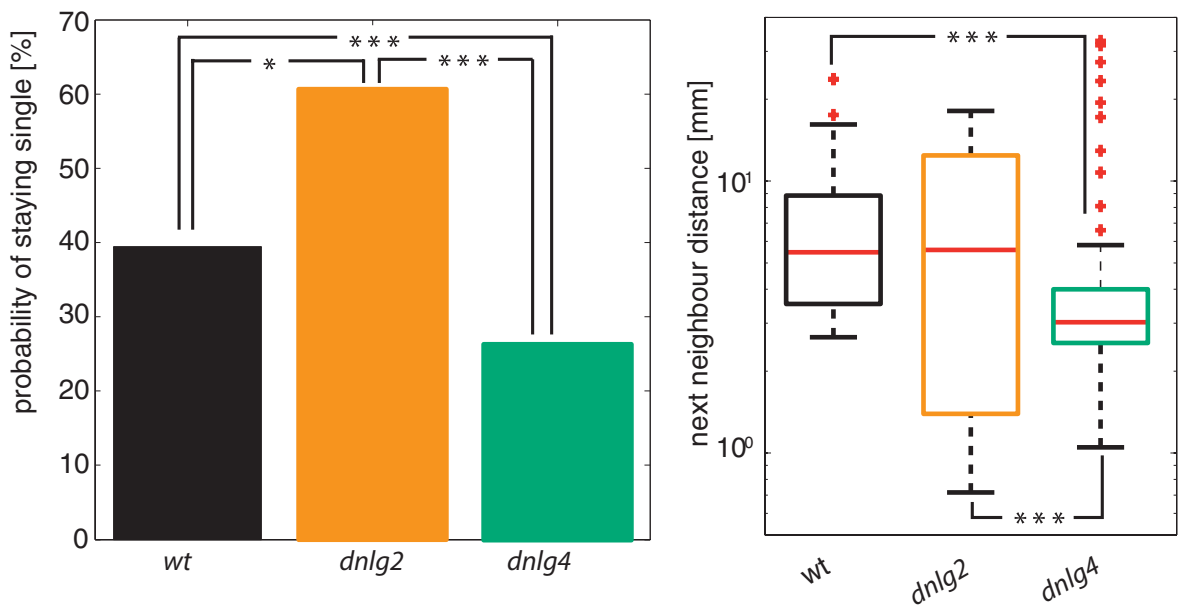

FIGURE 5 | Group interactions. (A) Stair histogram of different group sizes. The histograms are significantly different [two-sided Kolmogorov-Smirnov test corrected by Benjamini-Hochberg fdr; wt vs $d n \lg 2^{\text {KO17 }} p=0.0198 ;$ wt vs $d n \lg 4^{L L 01874 / D e f} p=3.2577 \times 10^{-4} ; d n / g 2^{K 017}$ vs $d n / g 4^{L L 01874 / D e f} p=2.5584 \times 10^{-9} ; N(w t)=104$,

$\left.N\left(d n / g 2^{K O 17}\right)=94, N\left(d n l g 4^{L L 1874 / D e f}\right)=119\right]$. (B) Median of the preferred group size of each individual. While Dnlg4-deficient flies aggregate in significantly larger groups than wt, Dnlg2-deficient flies aggregate in significantly smaller groups [Kolmogorov-Smirnov test corrected by Benjamini-Hochberg fdr; wt vs dnlg2 Ko17

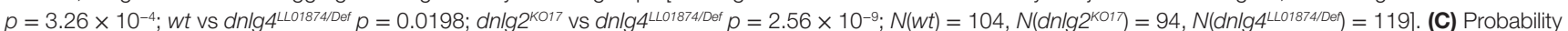
to stay alone during the group assay. Compared to wild-type (wt), Dnlg2-deficient flies ( $d n \lg 2^{\text {KO }}{ }^{7}$ ) have a significantly increased tendency to stay alone 60\% (only $39 \%$ in wt) (Fisher's exact test $p$-value 0.0065). In contrast, the chance to not associate in a group is at 24\% for Dnlg4-deficient flies [Fisher's exact test; wt vs $d n / g 4$ LL01874/Def $p=0.0304 ; d n l g 2^{K 017}$ vs $\left.d n \lg 4^{L L 01874 / D e f} p=5.6103 \times 10^{-7} ; N(w t)=104, N\left(d n l g 2^{K 017}\right)=94, N\left(d n l g 4^{L L 01874 / D e f}\right)=119\right]$. (D) Average interindividual distance to the nearest

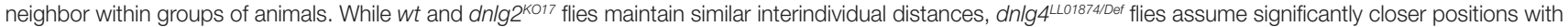
respect to $w t$ and $d n \lg 2^{K O 17}$.

In order to assess the requirements of Nlgs for the proper functionality of neural circuits, we analyzed the effects of mutations in $d \operatorname{lng} 2$ and $d \operatorname{lng} 4$ on walking, hearing, sound production, and social behavior. Electrophysiological recordings from antennal auditory nerves detected no differences in auditory sensitivity between wild type and mutant flies. Intact chemosensation can also be assumed, since males of both mutants correctly addressed females with courtship and males with agonistic behaviors in competitive courtship assays. In Drosophila, sex recognition and the assessment of female reproductive state has been demonstrated to largely depend on the detection of sex- and statespecific surface hydrocarbons $(79,80)$. In addition, $d n l g 2^{K O 17}$ - and

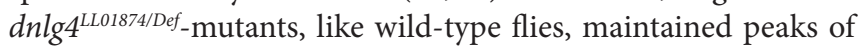

locomotor activity when lights were switched on or off $[(16,54)$, this study]. Nonetheless, the sleep rhythms of Dnlg2- and Dnlg4deficient flies were altered in an opposing manner, with Dnlg4deficient flies sleeping more often and shorter than $w t$, consistent with previous studies (54), and Dnlg2-deficient flies sleeping less often with longer duration (Figure 4). Notwithstanding seemingly normal sensory functions, both $d n l g 2^{\mathrm{KO} 17_{-}}$and $d n l g 4^{L L 01874 / D e f}$-mutants thus show opposing deficits in sleep.

Unlike other insect species, such as locusts and cockroaches, that contain both excitatory glutamatergic and inhibitory GABAergic motor neurons, Drosophila only possesses excitatory neuromuscular synapses (81). Synaptic expression of $d n \operatorname{lgs} 1,2$, and 3 and consequences for synaptic transmission resulting from 


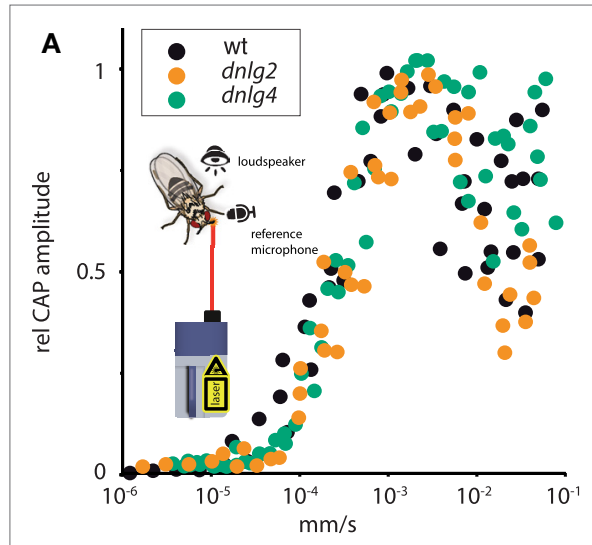

D

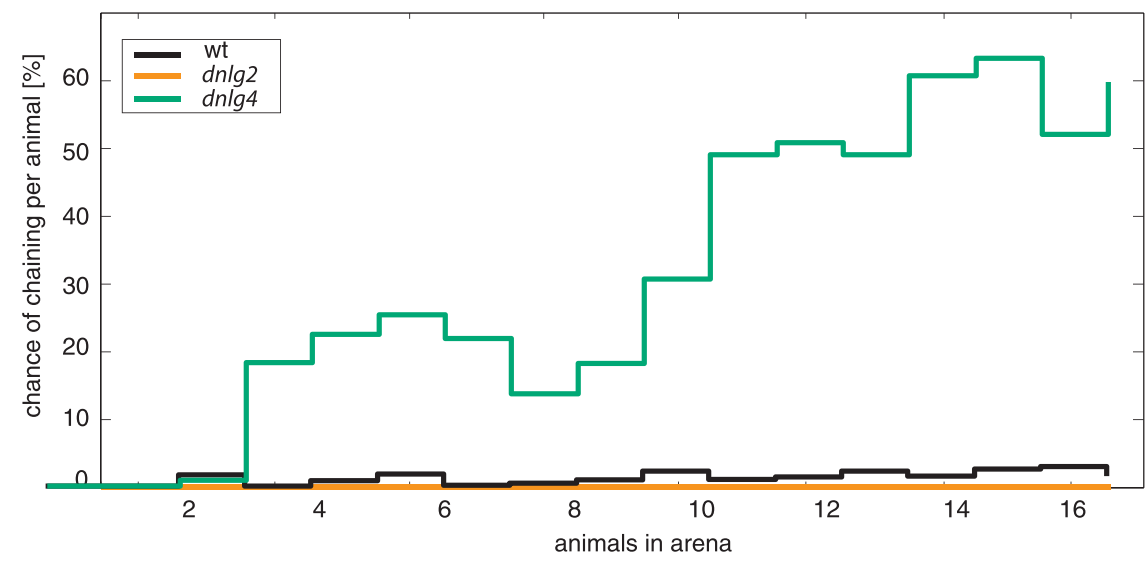

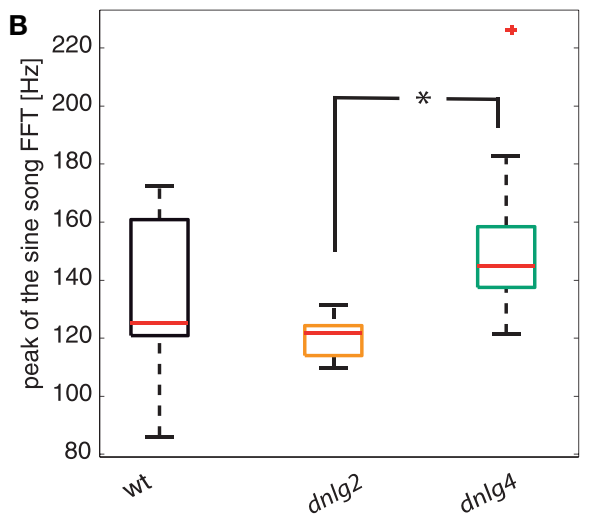

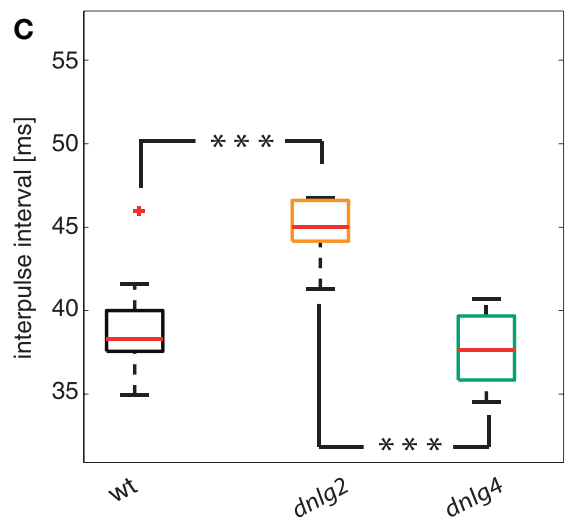

E

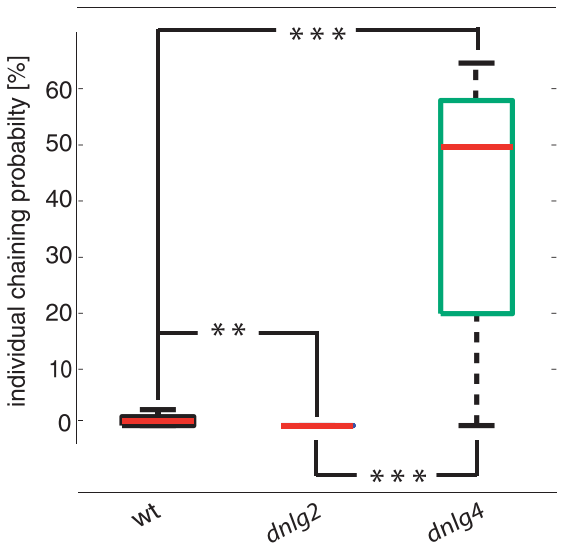

FIGURE 6 | Auditory function, courtship songs, and chaining. (A) Relative compound action potential (CAP) amplitude of tone-evoked auditory nerve responses plotted against the intensity of the tone. Tone frequencies were matched to the individual best frequencies of the antennal sound receiver. No distinct shift in the response threshold could be detected when comparing wild-type $(N=5)$, Dnlg4-deficient $(N=5)$, and Dnl2g-deficient $(N=3)$ flies. The insect shows a general schematic with which the antennal movements and sounds were recorded as references during the electrophysiological recordings. (B) Dominant frequency component of sine songs. Significance was calculated using Fisher's permutation test for differences of medians, corrected with Benjamini-Hochberg false detection

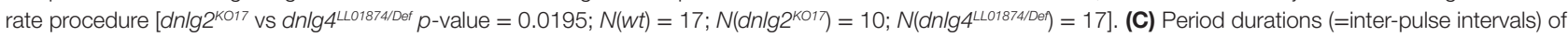
pulse songs [identical test for significance; wt vs $d n \lg 2^{K O 17} p=2 \times 10^{-4} ; d n l g 2^{K O 17}$ vs $d n \lg 4^{L L 01874 / D e f} p=8 \times 10^{-5} ; N(w t)=16, N\left(d n l g 2^{K O 17}\right)=10, N\left(d n l g 4^{L L 01874 / D e f}\right)=17$ ] (D) Probability of male-male chaining (a chain consists of two or more flies that chase each other with one extended wing) behavior per animal in dependence to the number of animals being present in the arena. In wt, the chance for male-male chaining behavior increases slightly with increasing numbers of present animals but

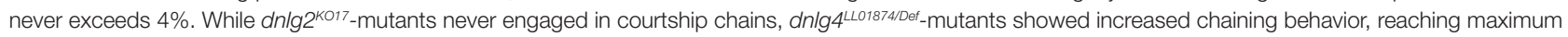
probabilities of over $60 \%\left[N(w t)=104, N\left(d n / g 2^{K 017}\right)=94, N\left(d n / g 4^{L L 01874 / D e f}\right)=119\right]$. (E) Boxplots depicting the individual probability to be part of male courtship chain. Dnlg4 shows a significantly increased chance, while $d n l g 4^{\lfloor L 01874 / D \text { ef }}$ shows a significant decrease $\left[\right.$ Kolmogorov-Smirnov test; $w t$ vs $d n l g 2^{K 017} p=7.3279 \times 10^{-5} ; w t$ vs $d n \lg 4^{\text {LL01874/Def }} p=6.0598 \times 10^{-9} ; d n \lg 2^{\text {KO17 }}$ vs $\left.d n \lg 4^{\text {LLO1874/Def }} p=1.7207 \times 10^{-9} ; N(w t)=104, N\left(d n \lg 2^{\text {KO17 }}\right)=94, N\left(d n l g 4^{L L 01874 / D e f}\right)=119\right]$.

the lack of these Nlgs at the Drosophila neuromuscular junction have been described in previous studies $(53,77,78,82)$. The $d n l g 2^{\mathrm{KO} 17}$-mutants used in our experiments displayed no defects that could be attributed to compromised neuromuscular transmission. Their walking behavior included all typical movement components (saccades, straight translation, and intermittent rest) that were combined in a coordinated fashion resembling that of wild-type flies (61). Moreover, CS pulses contained similar numbers of oscillations of the extended wing in $d n \lg 2^{K O 17}$-mutants and wild-type flies, indicating normal neuromuscular function. Altered repetition rates of courtship pulses and altered sine song frequencies in $d n \lg 2^{K O 17}$ point to alterations of central nervous circuits that determine the rhythm of wing movements. Along this line, Clyne and Miesenböck (83) demonstrated that initiation of sine and pulse song is triggered by descending brain neurons, whose activity synchronizes the intrinsic activity of thoracic pattern generators to a faster central clock. Avoidance of open areas is regarded as a measure for anxiety in various animal models (84-87). Wild-type Drosophila exhibit an obvious centrophobism that critically depends on the functionality of the mushroom bodies (55). While total ablation of mushroom bodies reduced centrophobism, specific inactivation of mushroom body $\gamma$-lobes increased centrophobistic behavior (55). Both, dnlg-mutant strains used in this study showed reduced centrophobic behavior (Figure 3) and $d n \lg 2$ is expressed in mushroom bodies along with $d \operatorname{lng} 4$ (unpublished immunocytochemical data by W. Xie), in the central complex (54). Both mushroom bodies and central complex are involved in the regulation of higher order social behaviors (55-59), so expression patterns seem consistent with the observed behavioral defects. 


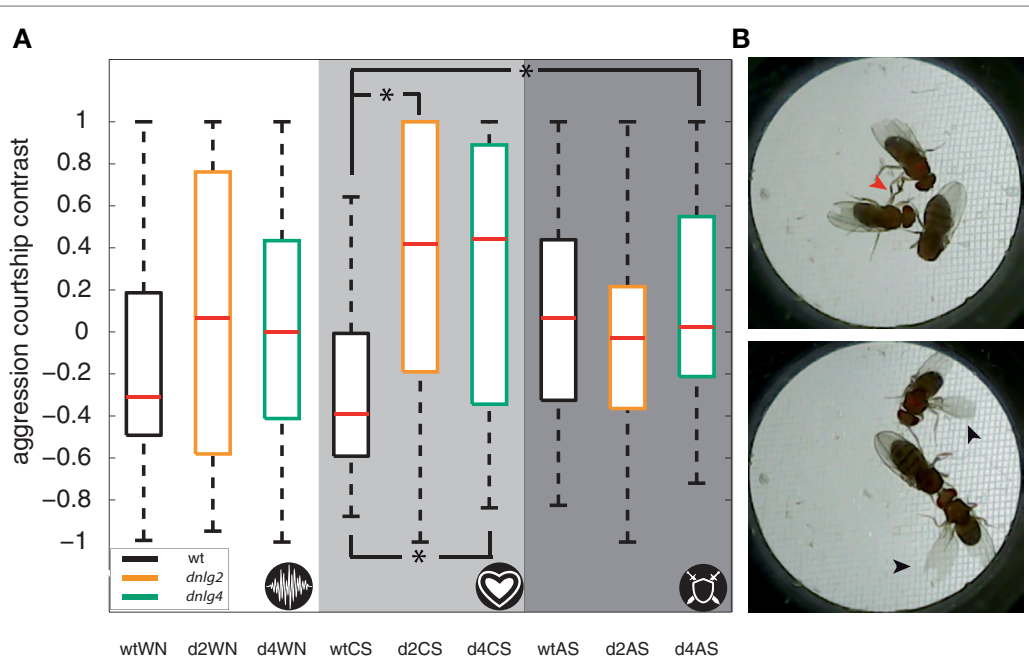

FIGURE 7 | Competitive courtship assay with acoustic stimulation. (A) Boxplots of the aggression courtship contrast (for definition, see Materials and Methods). The flies were stimulated by either white noise (white backdrop), courtship songs (CSs) (light gray backdrop), or aggression sound (dark gray background), as also indicated by the icon in lower right corner. Dnlg2- and Dnlg4-deficient flies reacted with significantly higher amounts of aggression behavior when stimulated with CSs than wt [Fisher's permutation test for differences of medians, corrected with Benjamini-Hochberg fdr; wt vs $d n / g 2^{K 017} p=0.024 ;$ wt vs $d n / g 4^{L 01874 / D e f} p=0.027$;

$\left.N(w t)=20 ; N\left(d n l g 4^{L L 01874 / D e f}\right)=20 ; N\left(d n l g 2^{K O 17}\right)=20\right](B)$ Two example frames that were manually assessed. The red arrow in the upper frame indicates leg fencing, a typical male-male aggression behavior. The black arrows in the lower frame indicate unilateral wing extension, a hallmark of courtship behavior.

During an unsupervised and data-derived group formation analysis, $20 \mathrm{~mm}$ emerged as the distance threshold for group interactions. This is nearly identical to the distance at which a conspecific fly is only detected by a single ommatidium in the complex eye of Drosophila $(61,88,89)$. Even though courtship and potentially other social contexts depend also on other sensory modalities [e.g., olfaction (90)], vision seems to be the most accurate and direct sense to judge the interindividual distance. Therefore, it is not surprising that group formation might be limited by the visual acuity of Drosophila. Aggregation of individuals and the formation of groups is a basic feature of social interaction, as for example oviposition in female Drosophila is dependent on group size (91). Compared to wild-type males, $d n l g 2^{\mathrm{KO} 17}$-mutants displayed a reduced tendency to form groups but those who accumulated in groups assumed similar minimal interindividual distances (Figure 5). In contrast, $d n \lg 4^{L L 01874 / D e f}$ mutants had a lower tendency to remain single, formed larger groups, and assumed closer positions to other group members.

Furthermore, this closer interindividual distance might have led to an increased formation of courtship chains in Dnlg4-deficient flies (Figure 6). Dnlg2-deficient flies showed a significantly lower chance of male-male courtship, which might be caused by their larger interindividual distance (Figure 6). It has been shown that CSs stimulate the formation of courtship chains $(92,93)$ and especially the inter-pulse interval of CSs has been identified as a critical factor for species recognition and attractiveness $(20,94)$, an alteration in song production might also lead to the chaining phenotype. Since $d n \lg 2^{\text {KOl7 }}$-mutant males produced songs with significantly prolonged inter-pulse intervals (Figure 6C), complete absence of chaining behavior could also have been a consequence of less attractive songs. Thus, the chaining phenotypes might be epiphenomena of the altered interindividual distance and CS production.
Absence of Dnlg2 and Dnlg4 altered social interactions of Drosophila males, without causing obvious impairments of sensory functions and execution of movements [this study, (16)]. Deficiency of Dnlg2 and Dnlg4, which seem to be differentially expressed at excitatory and inhibitory synapses, induced opposing deviations from wild-type behaviors in some behavioral paradigms, such as sleep rhythm, male chaining, group size, and interindividual distance. Other behavioral paradigms, such as center avoidance and stimulation with $w t$ CSs, revealed equally altered behavior in a non-opposing fashion. Thus, Dnlg2 and Dnlg4 may play different roles in the regulation of synaptic transmission within brain neuropils implicated in the social behavior of D. melanogaster.

Like fly Nlgs, mammalian ones are differentially expressed at different types of synapses, and deletion or overexpression of particular Nlgs resulted in altered proportions of excitatory vs inhibitory transmission in brain neuropils $(28,51)$. Both overrepresentation of excitation and overrepresentation of inhibition have been associated with ASD phenotypes (48) and have also been observed in mouse models of ASD (95-97). Targeted manipulation of Drosophila Dnlg2 and Dnlg4 functions in specific brain regions might help to identify the neural circuits that regulate social behaviors and to assess the role of Nlgs in the balance between neuronal excitation and inhibition.

\section{AUTHOR CONTRIBUTIONS}

All authors designed the study. KC, AH, RK, IG, NH, RH, and BG collected and analyzed the data, HG and BG designed the behavioral setups and data acquisition. $\mathrm{RH}$ and BG wrote the manuscript, and all authors edited and approved the manuscript. $\mathrm{KC}$ and $\mathrm{AH}$ contributed equally. 


\section{ACKNOWLEDGMENTS}

The authors thank Jan Hoffmann and Tobias Mühmer for their support with designing and constructing experimental setups. The authors thank Dr. Christian Spalthoff for his help concerning graphical design in all figures and especially Figure 1 and Nicola Schwedhelm-Domeyer for performing the qRT-PCR analysis. The authors acknowledge the generous support by the Open Access Publication Funds of the Göttingen University and the Cusanuswerk. The authors thank three hitherto unknown reviewers, whose constructive and thorough criticism improved our manuscript significantly.

\section{REFERENCES}

1. Denes AS, Jékely G, Steinmetz PRH, Raible F, Snyman H, Prud'homme B, et al. Molecular architecture of annelid nerve cord supports common origin of nervous system centralization in Bilateria. Cell (2007) 129:277-88. doi:10.1016/j.cell.2007.02.040

2. Tomer R, Denes AS, Tessmar-Raible K, Arendt D. Profiling by image registration reveals common origin of annelid mushroom bodies and vertebrate pallium. Cell (2010) 142:800-9. doi:10.1016/j.cell.2010.07.043

3. Strausfeld NJ, Hirth F. Deep homology of arthropod central complex and vertebrate basal ganglia. Science (2013) 340:157-61. doi:10.1126/ science. 1231828

4. Hartenstein V. The neuroendocrine system of invertebrates: a developmental and evolutionary perspective. J Endocrinol (2006) 190:555-70. doi:10.1677/ joe.1.06964

5. Tessmar-Raible K. The evolution of neurosecretory centers in bilaterian forebrains: insights from protostomes. Semin Cell Dev Biol (2007) 18:492-501. doi:10.1016/j.semcdb.2007.04.007

6. Wirmer A, Bradler S, Heinrich R. Homology of insect corpora allata and vertebrate adenohypophysis? Arthropod Struct Dev (2012) 41:409-17. doi:10.1016/j.asd.2012.04.003

7. Greenspan RJ, Dierick HA. 'Am not I a fly like thee?' From genes in fruit flies to behavior in humans. Hum Mol Genet (2004) 13(Suppl_2):R267-73. doi: $10.1093 / \mathrm{hmg} / \mathrm{ddh} 248$

8. McGurk L, Berson A, Bonini NM. Drosophila as an in vivo model for human neurodegenerative disease. Genetics (2015) 201(2):377-402. doi:10.1534/ genetics.115.179457

9. Reiter LT, Potocki L, Chien S, Gribskov M, Bier E. A systematic analysis of human disease-associated gene sequences in Drosophila melanogaster. Genome Res (2001) 11:1114-25. doi:10.1101/gr.169101

10. Feany MB, Bender WW. A Drosophila model of Parkinson's disease. Nature (2000) 404:394-8. doi:10.1038/35006074

11. Gatto CL, Broadie K. Drosophila modeling of heritable neurodevelopmental disorders. Curr Opin Neurobiol (2011) 21:834-41. doi:10.1016/j. conb.2011.04.009

12. Van Alphen B, Van Swinderen B. Drosophila strategies to study psychiatric disorders. Brain Res Bull (2013) 92:1-11. doi:10.1016/j.brainresbull.2011.09.007

13. van der Voet M, Nijhof B, Oortveld MA, Schenck A. Drosophila models of early onset cognitive disorders and their clinical applications. Neurosci Biobehav Rev (2014) 46(Pt 2):326-42. doi:10.1016/j.neubiorev.2014.01.013

14. Bolduc FV, Bell K, Cox H, Broadie KS, Tully T. Excess protein synthesis in Drosophila fragile X mutants impairs long-term memory. Nat Neurosci (2008) 11:1143-5. doi:10.1038/nn.2175

15. Wan L, Dockendorff TC, Jongens TA, Dreyfuss G. Characterization of dFMR1, a Drosophila melanogaster homolog of the fragile $\mathrm{X}$ mental retardation protein. Mol Cell Biol (2000) 20:8536-47. doi:10.1128/MCB.20.22.8536-8547.2000

16. Hahn N, Geurten B, Gurvich A, Piepenbrock D, Kästner A, Zanini D, et al. Monogenic heritable autism gene neuroligin impacts Drosophila social behaviour. Behav Brain Res (2013) 252:450-7. doi:10.1016/j.bbr.2013.06.020

17. Shao L, Shuai Y, Wang J, Feng S, Lu B, Li Z, et al. Schizophrenia susceptibility gene dysbindin regulates glutamatergic and dopaminergic functions

\section{FUNDING}

This study was supported by a grant from the German Science Foundation (DFG, SFB-889, A1, to MG). KC received a German Federal Scholarship Doctoral Grant awarded by the Cusanuswerk e.V.

\section{SUPPLEMENTARY MATERIAL}

The Supplementary Material for this article can be found online at http://journal.frontiersin.org/article/10.3389/fpsyt.2017.00113/ full\#supplementary-material.

via distinctive mechanisms in Drosophila. Proc Natl Acad Sci U S A (2011) 108:18831-6. doi:10.1073/pnas.1114569108

18. Zwarts L, Vulsteke V, Buhl E, Hodge JJL, Callaerts P. SlgA, encoded by the homolog of the human schizophrenia-associated gene $P R O D H$, acts in clock neurons to regulate Drosophila aggression. Dis Model Mech (2017) 10(6):705-16. doi:10.1242/dmm.027151

19. Ferguson L, Petty A, Rohrscheib C, Troup M, Kirszenblat L, Eyles DW, et al. Transient dysregulation of dopamine signaling in a developing drosophila arousal circuit permanently impairs behavioral responsiveness in adults. Front Psychiatry (2017) 8:22. doi:10.3389/fpsyt.2017.00022

20. Bennet-Clark HC, Ewing AW. The courtship songs of Drosophila. Behaviour (1968) 31:288-301. doi:10.1163/156853968X00298

21. Markow TA, Hanson SJ. Multivariate analysis of Drosophila courtship. Proc Natl Acad Sci U S A (1981) 78:430-4. doi:10.1073/pnas.78.1.430

22. Chen S, Lee AY, Bowens NM, Huber R, Kravitz EA. Fighting fruit flies: a model system for the study of aggression. Proc Natl Acad Sci U S A (2002) 99:5664-8. doi:10.1073/pnas.082102599

23. Fernández MP, Chan YB, Yew JY, Billeter JC, Dreisewerd K, Levine JD, et al. Pheromonal and behavioral cues trigger male-to-female aggression in Drosophila. PLoS Biol (2010) 8:e1000541. doi:10.1371/journal. pbio. 1000541

24. Tauber E, Eberl DF. Acoustic communication in Drosophila. Behav Processes (2003) 64:197-210. doi:10.1016/S0376-6357(03)00135-9

25. Kahsai L, Zars T. Learning and memory in Drosophila: behavior, genetics, and neural systems. Int Rev Neurobiol (2011) 99:139-67. doi:10.1016/ B978-0-12-387003-2.00006-9

26. Pick S, Strauss R. Goal-driven behavioral adaptations in gap-climbing Drosophila. Curr Biol (2005) 15:1473-8. doi:10.1016/j.cub.2005.07.022

27. St Johnston D. Using mutants, knockdowns, and transgenesis to investigate gene function in Drosophila. Wiley Interdiscip Rev Dev Biol (2013) 2:587-613. doi:10.1002/wdev.101

28. Chubykin AA, Atasoy D, Etherton MR, Brose N, Kavalali ET, Gibson JR, et al. Activity-dependent validation of excitatory versus inhibitory synapses by neuroligin-1 versus neuroligin-2. Neuron (2007) 54:919-31. doi:10.1016/j. neuron.2007.05.029

29. Ichtchenko K, Nguyen T, Südhof TC. Structures, alternative splicing, and neurexin binding of multiple neuroligins. J Biol Chem (1996) 271:2676-82. doi:10.1074/jbc.271.5.2676

30. Südhof TC, Malenka RC. Understanding synapses: past, present, and future. Neuron (2008) 60:469-76. doi:10.1016/j.neuron.2008.10.011

31. Varoqueaux F, Aramuni G, Rawson RL, Mohrmann R, Missler M, Gottmann K, et al. Neuroligins determine synapse maturation and function. Neuron (2006) 51:741-54. doi:10.1016/j.neuron.2006.09.003

32. Reissner C, Runkel F, Missler M. Neurexins. Genome Biol (2013) 14:213. doi:10.1186/gb-2013-14-9-213

33. Dean C, Dresbach T. Neuroligins and neurexins: linking cell adhesion, synapse formation and cognitive function. Trends Neurosci (2006) 29(1):21-9. doi:10.1016/j.tins.2005.11.003

34. Krueger DD, Tuffy LP, Papadopoulos T, Brose N. The role of neurexins and neuroligins in the formation, maturation, and function of vertebrate synapses. Curr Opin Neurobiol (2012) 22:412-22. doi:10.1016/j.conb.2012.02.012 
35. Südhof TC. Neuroligins and neurexins link synaptic function to cognitive disease. Nature (2008) 455:903-11. doi:10.1038/nature07456

36. Cowling DE, Burnet B. Courtship songs and genetic control of their acoustic characteristics in sibling species of the Drosophila melanogaster subgroup. Anim Behav (1981) 29:924-35. doi:10.1016/S0003-3472(81)80030-9

37. Varoqueaux F, Jamain S, Brose N. Neuroligin 2 is exclusively localized to inhibitory synapses. Eur J Cell Biol (2004) 83:449-56. doi:10.1078/0171-9335-00410

38. Knight D, Xie W, Boulianne GL. Neurexins and neuroligins: recent insights from invertebrates. Mol Neurobiol (2011) 44(3):426-40. doi:10.1007/ s12035-011-8213-1

39. Maćkowiak M, Mordalska P, Wędzony K. Neuroligins, synapse balance and neuropsychiatric disorders. Pharmacol Rep (2014) 66:830-5. doi:10.1016/j. pharep.2014.04.011

40. Jamain S, Quach H, Betancur C, Råstam M, Colineaux C, Gillberg IC, et al. Mutations of the X-linked genes encoding neuroligins NLGN3 and NLGN4 are associated with autism. Nat Genet (2003) 34:27-9. doi:10.1038/ng1136

41. Jamain S, Radyushkin K, Hammerschmidt K, Granon S, Boretius S, Varoqueaux F, et al. Reduced social interaction and ultrasonic communication in a mouse model of monogenic heritable autism. Proc Natl Acad Sci U S A (2008) 105:1710-5. doi:10.1073/pnas.0711555105

42. Laumonnier F, Bonnet-Brilhault F, Gomot M, Blanc R, David A, Moizard M-P, et al. X-linked mental retardation and autism are associated with a mutation in the NLGN4 gene, a member of the neuroligin family. Am J Hum Genet (2004) 74(3):552-7. doi:10.1086/382137

43. Ornoy A, Weinstein-Fudim L, Ergaz Z. Genetic syndromes, maternal diseases and antenatal factors associated with autism spectrum disorders (ASD). Front Neurosci (2016) 10:316. doi:10.3389/fnins.2016.00316

44. Ey E, Leblond CS, Bourgeron T. Behavioral profiles of mouse models for autism spectrum disorders. Autism Res (2011) 4:5-16. doi:10.1002/aur.175

45. Bourgeron T. From the genetic architecture to synaptic plasticity in autism spectrum disorder. Nat Rev Neurosci (2015) 16(9):551-63. doi:10.1038/ nrn3992

46. Lee E, Lee J, Kim E. Excitation/inhibition imbalance in animal models of autism spectrum disorders. Biol Psychiatry (2017) 81:838-47. doi:10.1016/j. biopsych.2016.05.011

47. Rubenstein JLR, Merzenich MM. Model of autism: increased ratio of excitation/inhibition in key neural systems. Genes Brain Behav (2003) 2:255-67. doi:10.1034/j.1601-183X.2003.00037.x

48. Dickinson A, Jones M, Milne E. Measuring neural excitation and inhibition in autism: different approaches, different findings and different interpretations. Brain Res (2016) 1648:277-89. doi:10.1016/j.brainres.2016.07.011

49. Chih B, Engelman H, Scheiffele P. Control of excitatory and inhibitory synapse formation by neuroligins. Science (2005) 307:1324-8. doi:10.1126/ science. 1107470

50. Gogolla N, LeBlanc JJ, Quast KB, Südhof TC, Fagiolini M, Hensch TK. Common circuit defect of excitatory-inhibitory balance in mouse models of autism. J Neurodev Disord (2009) 1:9023. doi:10.1007/s11689-009-9023-x

51. Graf ER, Zhang X, Jin S-X, Linhoff MW, Craig AM. Neurexins induce differentiation of GABA and glutamate postsynaptic specializations via neuroligins. Cell (2004) 119:1013-26. doi:10.1016/j.cell.2004.11.035

52. Han S, Tai C, Westenbroek RE, Yu FH, Cheah CS, Potter GB, et al. Autistic-like behaviour in Scnla \pm mice and rescue by enhanced GABA-mediated neurotransmission. Nature (2012) 489:385-90. doi:10.1038/nature11356

53. Sun M, Xing G, Yuan L, Gan G, Knight D, With SI, et al. Neuroligin 2 is required for synapse development and function at the Drosophila neuromuscular junction. J Neurosci (2011) 31:687-99. doi:10.1523/JNEUROSCI.3854-10.2011

54. Li Y, Zhou Z, Zhang X, Tong H, Li P, Zhang ZC, et al. Drosophila neuroligin 4 regulates sleep through modulating GABA transmission. J Neurosci (2013) 33:15545-54. doi:10.1523/JNEUROSCI.0819-13.2013

55. Besson M, Martin J-R. Centrophobism/thigmotaxis, a new role for the mushroom bodies in Drosophila. J Neurobiol (2005) 62:386-96. doi:10.1002/ neu.20111

56. Joiner WJ, Crocker A, White BH, Sehgal A. Sleep in Drosophila is regulated by adult mushroom bodies. Nature (2006) 441:757-60. doi:10.1038/nature04811

57. Ofstad TA, Zuker CS, Reiser MB. Visual place learning in Drosophila melanogaster. Nature (2011) 474:204-7. doi:10.1038/nature10131

58. Redt-Clouet C, Trannoy S, Boulanger A, Tokmatcheva E, Savvateeva-Popova E, Parmentier M-L, et al. Mushroom body neuronal remodelling is necessary for short-term but not for long-term courtship memory in Drosophila. Eur J Neurosci (2012) 35:1684-91. doi:10.1111/j. 1460-9568.2012.08103.x

59. Tully T, Quinn WG. Classical conditioning and retention in normal and mutant Drosophila melanogaster. JComp Physiol A (1985) 157:263-77. doi:10.1007/BF01350033

60. Geurten BRH, Kern R, Braun E, Egelhaaf M. A syntax of hoverfly flight prototypes. J Exp Biol (2010) 213:2461-75. doi:10.1242/jeb.036079

61. Geurten BRH, Jähde P, Corthals K, Göpfert MC. Saccadic body turns in walking Drosophila. Front Behav Neurosci (2014) 8:365. doi:10.3389/fnbeh.2014.00365

62. Gras H. A multiaxis device for in-focus manipulation of objects under a dissecting microscope. J Microsc (2014) 256:1-5. doi:10.1111/jmi.12152

63. Göpfert MC, Robert D. The mechanical basis of Drosophila audition. J Exp Biol (2002) 205:1199-208.

64. Effertz T, Wiek R, Göpfert MC. NompC TRP channel is essential for Drosophila sound receptor function. Curr Biol (2011) 21:592-7. doi:10.1016/j. cub.2011.02.048

65. Kamikouchi A, Inagaki HK, Effertz T, Hendrich O, Fiala A, Göpfert MC, et al. The neural basis of Drosophila gravity-sensing and hearing. Nature (2009) 458:165-71. doi:10.1038/nature07810

66. Kuo T-H, Yew JY, Fedina TY, Dreisewerd K, Dierick HA, Pletcher SD. Aging modulates cuticular hydrocarbons and sexual attractiveness in Drosophila melanogaster. J Exp Biol (2012) 215:814-21. doi:10.1242/jeb.064980

67. Lin HH, Cao DS, Sethi S, Zeng Z, Chin JSR, Chakraborty TS, et al. Hormonal modulation of pheromone detection enhances male courtship success. Neuron (2016) 90:1272-85. doi:10.1016/j.neuron.2016.05.004

68. Kvelland I. Some observations on the mating activity and fertility of Drosophila melanogaster males. Hereditas (1965) 53:281-306. doi:10.111 1/j.1601-5223.1965.tb01997.x

69. Jonsson T, Kravitz EA, Heinrich R. Sound production during agonistic behavior of male Drosophila melanogaster. Fly (2011) 5(1):29-38. doi:10.4161/ fly.5.1.13713

70. Braun E, Geurten B, Egelhaaf M. Identifying prototypical components in behaviour using clustering algorithms. PLoS One (2010) 5:15. doi:10.1371/ journal.pone.0009361

71. Benjamini $Y$, Hochberg Y. Controlling the false discovery rate: a practical and powerful approach to multiple testing. J R Stat Soc B (1995) 57(1):289-300. doi:10.2307/2346101

72. Helmer D, Geurten BRH, Dehnhardt G, Hanke FD. Saccadic movement strategy in common cuttlefish (Sepia officinalis). Front Physiol (2017) 7:660. doi:10.3389/FPHYS.2016.00660

73. Colomb J, Reiter L, Blaszkiewicz J, Wessnitzer J, Brembs B. Open source tracking and analysis of adult Drosophila locomotion in Buridan's paradigm with and without visual targets. PLoS One (2012) 7:e42247. doi:10.1371/journal. pone. 0042247

74. Götz KG, Biesinger R. Centrophobism in Drosophila melanogaster. J Comp Physiol A (1985) 156:329-37. doi:10.1007/BF00610726

75. Ryner LC, Goodwin SF, Castrillon DH, Anand A, Villella A, Baker BS, et al. Control of male sexual behavior and sexual orientation in Drosophila by the fruitless gene. Cell (1996) 87:1079-89. doi:10.1016/ S0092-8674(00)81802-4

76. Versteven M, Vanden Broeck L, Geurten B, Zwarts L, Decraecker L, Beelen M, et al. Hearing regulates Drosophila aggression. Proc Natl Acad Sci U S A (2017) 114:1958-63. doi:10.1073/pnas.1605946114

77. Banovic D, Khorramshahi O, Owald D, Wichmann C, Riedt T, Fouquet W, et al. Drosophila neuroligin 1 promotes growth and postsynaptic differentiation at glutamatergic neuromuscular junctions. Neuron (2010) 66:724-38. doi:10.1016/j.neuron.2010.05.020

78. Xing G, Gan G, Chen D, Sun M, Yi J, Lv H, et al. Drosophila neuroligin3 regulates neuromuscular junction development and synaptic differentiation. J Biol Chem (2014) 289:31867-77. doi:10.1074/jbc.M114.574897

79. Thistle R, Cameron P, Ghorayshi A, Dennison L, Scott K. Contact chemoreceptors mediate male-male repulsion and male-female attraction during Drosophila courtship. Cell (2012) 149:1140-51. doi:10.1016/j.cell.2012. 03.045

80. van der Goes van Naters W, Carlson JR. Receptors and neurons for fly odors in Drosophila. Curr Biol (2007) 17:606-12. doi:10.1016/j.cub.2007.02.043

81. Enell L, Hamasaka Y, Kolodziejczyk A, Nässel DR. $\gamma$-Aminobutyric acid (GABA) signaling components in Drosophila: immunocytochemical localization of $G A B A(B)$ receptors in relation to the $G A B A(A)$ receptor subunit 
RDL and a vesicular GABA transporter. J Comp Neurol (2007) 505:18-31. doi:10.1002/cne.21472

82. Chen Y-C, Lin YQ, Banerjee S, Venken K, Li J, Ismat A, et al. Drosophila neuroligin 2 is required presynaptically and postsynaptically for proper synaptic differentiation and synaptic transmission. J Neurosci (2012) 32:16018-30. doi:10.1523/JNEUROSCI.1685-12.2012

83. Clyne JD, Miesenböck G. Sex-specific control and tuning of the pattern generator for courtship song in Drosophila. Cell (2008) 133:354-63. doi:10.1016/j. cell.2008.01.050

84. Clarke CH, Jones RB. Effects of prior video stimulation on open-field behaviour in domestic chicks. Appl Anim Behav Sci (2000) 66:107-17. doi:10.1016/S0168-1591(99)00071-4

85. Crawley JN. Exploratory behavior models of anxiety in mice. Neurosci Biobehav Rev (1985) 9:37-44. doi:10.1016/0149-7634(85)90030-2

86. Creed RP, Miller JR. Interpreting animal wall-following behavior. Experientia (1990) 46:758-61. doi:10.1007/BF01939959

87. Pollack Carducci J, Jakob EM. Rearing environment affects behaviour of jumping spiders. Anim Behav (2000) 59:39-46. doi:10.1006/anbe.1999.1282

88. Buchner E. Dunkelanregung des stationaeren Flugs der Fruchtfliege Drosophila. Ph.D. Thesis, University of Tübingen (1971).

89. Gonzalez-Bellido PT, Wardill TJ, Juusola M. Compound eyes and retinal information processing in miniature dipteran species match their specific ecological demands. Proc Natl Acad Sci U S A (2011) 108:4224-9. doi:10.1073/ pnas. 1014438108

90. Schneider J, Dickinson MH, Levine JD. Social structures depend on innate determinants and chemosensory processing in Drosophila. Proc Natl Acad Sci US A (2012) 109:17174-9. doi:10.1073/pnas.1121252109

91. Wertheim B, Allemand R, Vet LEM, Dicke M. Effects of aggregation pheromone on individual behaviour and food web interactions: a field study on Drosophila. Ecol Entomol (2006) 31:216-26. doi:10.1111/J.1365-2311.2006. 00757.X
92. Yoon J, Matsuo E, Yamada D, Mizuno H, Morimoto T, Miyakawa H, et al. Selectivity and plasticity in a sound-evoked male-male interaction in Drosophila. PLoS One (2013) 8:e74289. doi:10.1371/journal.pone.0074289

93. Zhang SD, Odenwald WF. Misexpression of the white (w) gene triggers malemale courtship in Drosophila. Proc Natl Acad Sci U S A (1995) 92:5525-9. doi:10.1073/pnas.92.12.5525

94. Schilcher FV. The function of pulse song and sine song in the courtship of Drosophila melanogaster. Anim Behav (1976) 3:622-5. doi:10.1016/ S0003-3472(76)80076-0

95. Blundell J, Blaiss CA, Etherton MR, Espinosa F, Tabuchi K, Walz C, et al. Neuroligin-1 deletion results in impaired spatial memory and increased repetitive behavior. J Neurosci (2010) 30:2115-29. doi:10.1523/ JNEUROSCI.4517-09.2010

96. Markram K, Rinaldi T, La Mendola D, Sandi C, Markram H. Abnormal fear conditioning and amygdala processing in an animal model of autism. Neuropsychopharmacology (2008) 33:901-12. doi:10.1038/sj.npp.1301453

97. Tabuchi K, Blundell J, Etherton MR, Hammer RE, Liu X, Powell CM, et al. A neuroligin-3 mutation implicated in autism increases inhibitory synaptic transmission in mice. Science (2007) 318:71-6. doi:10.1126/science.1146221

Conflict of Interest Statement: The authors declare that the research was conducted in the absence of any commercial or financial relationships that could be construed as a potential conflict of interest.

Copyright $\odot 2017$ Corthals, Heukamp, Kossen, Großhennig, Hahn, Gras, Göpfert, Heinrich and Geurten. This is an open-access article distributed under the terms of the Creative Commons Attribution License (CC BY). The use, distribution or reproduction in other forums is permitted, provided the original author(s) or licensor are credited and that the original publication in this journal is cited, in accordance with accepted academic practice. No use, distribution or reproduction is permitted which does not comply with these terms. 